\title{
СУЩНОСТЬ ВЫСОКОТЕХНОЛОГИЧНОГО ПРЕДПРИЯТИЯ И СОВРЕМЕННЫЕ ПОДХОДЫ К ОПРЕДЕЛЕНИЮ
}

\section{(c) 2021 Шарафутдинова Лилия Ражаповна}

аспирант кафедры экономики и управления предприятиями и производственными комплексами Санкт-Петербургский государственный экономический университет, Россия, Санкт-Петербург

E-mail: liliya.sharafutdinova22@gmail.com

Несмотря на существующие общие представления о высокотехнологичном производстве, дискуссионным является вопрос определения высокотехнологичного предприятия. В статье представлены результаты исследования подходов к определению высокотехнологичного предприятия. Выявлены отличительные особенности и наиболее важные критерии развития данных предприятий.

Ключевые слова: высокотехнологичное предприятие, промышленность, высокотехнологичная отрасль, четвертая промышленная революция, высокие технологии, стратегия

Развитие экономики во многом определяется темпами развития предприятий высокотехнологичных и наукоемких сфер деятельности. Результат развития экономики и общества, научно-технический прогресс зависят от эффективности реализации производств высокого технологического уровня. Проблема развития высокотехнологичных предприятий является актуальной не только для самих предприятий, но и конкурентоспособности национальной экономики.

Наукоемкость производства, внедрение новейших технологий и методов стали играть ведущую роль в обеспечении роста экономики. Под воздействием роста наукоемкости производства сформировались группы отраслей промышленности, обозначаемые как «высокотехнологичные».

В период четвертой промышленной революции движущей силой являются цифровые технологии, трансформация промышленного производства, развитие сетевых форм хозяйствования, способствующие технологическим изменениям и новой индустриализации [16]. При исследовании высокотехнологичных предприятий дискуссионным является вопрос корректного определения самой сущности высокотехнологичного предприятием. Несмотря на существующие общие представления о высокотехнологичной сфере, отсутствие объективных критериев определения предприятия как высокотехнологичного вызывает сложности при исследовании предприятий, их отличий от предприятий невысокотехнологичного сектора и др. [7]
Таким образом целью данной статьи является анализ существующих подходов к определению высокотехнологичного предприятия и выявление основных его отличительных особенностей.

При анализе сущности и значения высокотехнологичных предприятий применимы различные походы, в частности, этимологический, отраслевой, продуктовый, патентный, параметрический. Рассмотрим этимологический подход, выделив определение понятий «технология» и «высокая технология». В соответствии с определением Н.Дика «технология - это совокупность методов обработки, производства предметов и вещей» [10].

В соответствии с методологией $\mathrm{OOH}$ технология включает материальные и нематериальные компоненты - методы и технику производства товаров и услуг, реализованную технологию, оборудование, машины, сооружения, продукцию с высокими технико-экономическими параметрами [19].

Высокие технологии рассматриваются как:

- новый вид деятельности;

- наукоемкая отрасль, воздействующая на смежные отрасли;

- деятельность, основанная на фундаментальных и прикладных исследованиях, с высокой долей занятости высококвалифицированных сотрудников и высокой долей затрат НИОКР в производстве. Высокие технологии основаны на результатах фундаментальных и прикладных научных исследований, являются ядром производства наукоёмкой продукции, при этом тех- 
нология считается высокой пока не заменится новой, усовершенствованной.

Отраслевой подход предполагает классификацию отраслей промышленности по показателю интенсивности НИОКР, отнесения отрасли к высокотехнологичной с учетом «производства» технологии или её использования. Широко распространенными являются классификации по отраслям на высоко-, средне- и низкотехнологичные. При разработке классификации были исследованы 22 сектора обрабатывающей промышленности в 10 странах ОЭСР с учетом показателя добавленной стоимости, интенсивности НИОКР, на основе сравнения прямой и косвенной интенсивности НИОКР. В результате отрасли промышленности классифицированы по четырем группам производства: высокотехнологичные, средне-высокотехнологичные, средне-низкотехнологичные, низкотехнологичные. Косвенный и прямой показатели интенсивности отражают ранжирование отраслей по производству технологии или ее использованию. Высокотехнологичные отрасли промышленности имеют более высокую интенсивность в области НИОКР [27].

Развитие высокотехнологичного производства привело к изменению определения технологического уровня отрасли. Так, классификация производилась путем оценки расходов на НИОКР к добавленной стоимости продукции и валовому объему производства. В соответствии с данной методикой, к высокотехнологичным относятся отрасли с соотношением затрат НИОКР более 3,5\% к объему выпуска.

В соответствии со следующим документом [1] дано определение наукоемких высокотехнологичных отраслей (производств) «...отрасли, сферы и виды экономической деятельности, результатом которой является продукция (товары, работы, услуги) со значительной добавленной стоимостью, полученной за счет применения достижений науки, технологий и техники, характеризующаяся высокой долей внутренних затрат на исследования и разработки в стоимостном объеме производства такой продукции». В классификациях ОЭСР, Национального фонда США, ООН, критерием отнесения к высокотехнологичным отраслям является высокий уровень технологического развития, определяемый отношением затрат на НИОКР к валовой добавленной стоимости. Критерием наукоёмкой отрасли служит доля лиц с высшим образованием в составе сотрудников [20].

В Российской Федерации состав высокотехнологичных и наукоёмких отраслей сформирован на основе группировок, рекомендованных Евростатом и ОЭСР, что позволяет сопоставлять расчеты, но с учётом национальных особенностей [2]. Различие в отнесении отрасли к высокотехнологичной обусловлено границами отраслевого деления в разных странах, тенденциями трансформации реального сектора (интеграция, специализация, выделение новых видов деятельности и др.). В таблице 1 представлены наиболее широко используемые классификации высокотехнологичных отраслей.

Важно отметить, что доля продукции высокотехнологичных и наукоемких отраслей в ВВП России колеблется; несмотря на увеличение за последние пять лет, значение 2019 года равно такому же показателю в 2014 году - 21,6\% (рисунок 1).

В развитых странах доля наукоемких отраслей превышает 40\%. Санкционные ограничения, общая стагнация российской экономики оказали негативное влияние на развитие науки и технологий в ВВП.

К странам с высокой долей высокотехнологичной продукции относятся: Япония, Франция, Великобритания, США, Германия, среди развивающихся стран - Китай, Индия. В соответствии с имеющимися данными экспорт высокотехнологичной продукции, не превышающий 7,5\%, относится к низким показателям [9].

Как отмечено было выше, объем затрат на НИОКР является одним из результирующих показателей классификации высокотехнологичных отраслей (Таблица 3).

Объём расходов на НИОКР в России находится на низком уровне. Доля внутренних затрат составляет около 1\%, что значительно ниже чем в европейских странах, США и др. Около 1\% составляет доля предприятий, получивших государственную поддержку на проведение НИОКР. В то же время показатель интенсивности НИОКР как основа отраслевого подхода не дает данных о результате деятельности предприятия. Включение предприятия в отрасль, относящуюся к высокотехнологичной не подтверждает высокотехнологичность самого предприятия. При таком подходе достаточно сложно оценить конкурентные преимущества предприятия конкретной высокотехнологичной отрасли. Также, если критерием наукоёмкой отрасли является 
Таблица 1. Отнесение отраслей промышленности к высокотехнологичным по различным классификациям

\begin{tabular}{|c|c|c|c|}
\hline ОЭСР & $\mathrm{OOH}$ & $\begin{array}{l}\text { Национальный } \\
\text { научный фонд }\end{array}$ & $\mathbf{P \Phi}$ \\
\hline Авиакосмическая & $\begin{array}{l}\text { Химические изделия и } \\
\text { продукты; }\end{array}$ & $\begin{array}{l}\text { Ракетно-космическая и } \\
\text { авиационная промыш- } \\
\text { ленности }\end{array}$ & $\begin{array}{l}\text { Производство летатель- } \\
\text { ных аппаратов }\end{array}$ \\
\hline Фармацевтика & $\begin{array}{l}\text { Медицинские, точные и } \\
\text { оптические инструменты }\end{array}$ & $\begin{array}{l}\text { Компьютеры и телеком- } \\
\text { муникации }\end{array}$ & $\begin{array}{l}\text { Производство фармацев- } \\
\text { тической продукции и } \\
\text { медицинских изделий }\end{array}$ \\
\hline $\begin{array}{l}\text { Производство меди- } \\
\text { цинского оборудования, } \\
\text { точных оптических при- } \\
\text { боров, а также часов }\end{array}$ & $\begin{array}{l}\text { Электроника, оборудова- } \\
\text { ние для радио, телевиде- } \\
\text { ния и связи }\end{array}$ & Оптоэлектроника & $\begin{array}{l}\text { Производство средств } \\
\text { измерения и контроля }\end{array}$ \\
\hline $\begin{array}{l}\text { Производство радио- и } \\
\text { телекоммуникационного } \\
\text { оборудования }\end{array}$ & $\begin{array}{l}\text { Офисная, бухгалтерская и } \\
\text { комп. техника }\end{array}$ & $\begin{array}{l}\text { Электроника, производ- } \\
\text { ства, связанные с ком- } \\
\text { пьютеризацией }\end{array}$ & $\begin{array}{l}\text { Электронная и радиоэ- } \\
\text { лектронная промышлен- } \\
\text { ность }\end{array}$ \\
\hline \multirow[t]{4}{*}{$\begin{array}{l}\text { Ядерные технологии, } \\
\text { Биотехнологии, наука о } \\
\text { жизни. }\end{array}$} & \multirow{4}{*}{$\begin{array}{l}\text { Автомобили, прицепы } \\
\text { и полуприцепы, другое } \\
\text { транспортное оборудо- } \\
\text { вание }\end{array}$} & $\begin{array}{l}\text { Производство военной } \\
\text { техники и оружия, новых } \\
\text { материалов, }\end{array}$ & $\begin{array}{l}\text { Производство офисного } \\
\text { оборудования и вычисли- } \\
\text { тельной техники. }\end{array}$ \\
\hline & & & $\begin{array}{l}\text { Энергетическое машино- } \\
\text { строение }\end{array}$ \\
\hline & & & $\begin{array}{l}\text { Атомный энергопромыш- } \\
\text { ленный комплекс }\end{array}$ \\
\hline & & & Судостроение \\
\hline
\end{tabular}

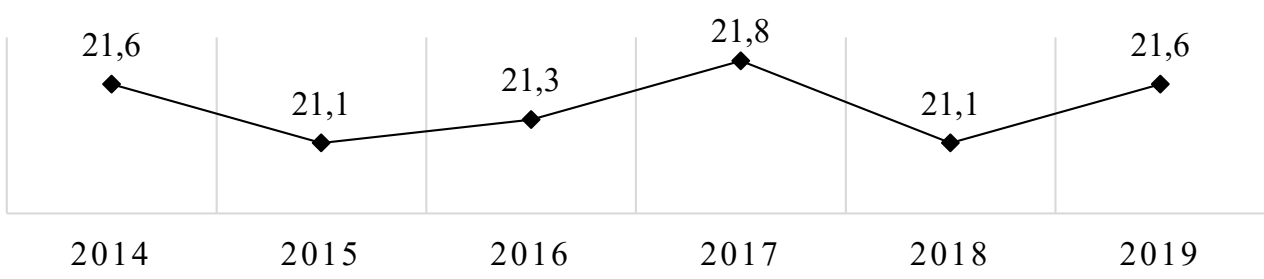

Рисунок 1. Доля продукции высокотехнологичных и наукоемких отраслей в валовом внутреннем продукте (данные по ОКВЭД 2, в\% к итогу) [20]

Таблица 2. Доля продукции высокотехнологичных и наукоемких отраслей в валовом внутреннем продукте [9].

\begin{tabular}{|c|c|c|c|c|c|c|}
\hline & \multicolumn{3}{|c|}{ Доля в ВВП, \% } & \multicolumn{3}{|c|}{$\begin{array}{c}\text { Доля в общем объеме товарного } \\
\text { экспорта, \% }\end{array}$} \\
\hline & 2000 & 2008 & 2015 & 2000 & 2008 & 2016 \\
\hline Российская Федерация & 32,7 & 24,6 & 25,6 & 16,1 & 6,5 & 10,7 \\
\hline Бразилия & 35,0 & 37,2 & 35,2 & 18,7 & 11,6 & 13,4 \\
\hline Индия & 41,3 & 38,5 & 37,9 & 6,3 & 6,8 & 7,1 \\
\hline Китай & 42,9 & 41,4 & 41,4 & 19,0 & 25,6 & 25,2 \\
\hline Великобритания & 43,5 & 44,9 & 47,4 & 32,4 & 18,5 & 21,8 \\
\hline Германия & 54,5 & 60,3 & 61,4 & 18,6 & 13,3 & 16,9 \\
\hline Италия & 38,1 & 40,1 & 42,7 & 9,5 & 6,4 & 7,5 \\
\hline Канада & 44,0 & 37,9 & 30,6 & 17,7 & 13,6 & 12,9 \\
\hline США & 51,0 & 51,3 & 41,2 & 33,7 & 25,9 & 20,0 \\
\hline Франция & 46,3 & 47,2 & 49,4 & 24,6 & 20,0 & 26,7 \\
\hline Япония & 52 & 55,6 & 55,3 & 28,7 & 17,3 & 16,2 \\
\hline Испания & 34,1 & 34,3 & 40,2 & 8,0 & 5,3 & 7,0 \\
\hline
\end{tabular}


Таблица 3. Внутренние затраты на исследования и разработки в целом по Российской Федерации (\%) [20]

\begin{tabular}{|c|c|c|c|c|c|}
\hline Показатель & 2014 & 2015 & 2016 & 2017 & 2018 \\
\hline $\begin{array}{l}\text { Доля внутренних затрат на исследования и разработки в } \\
\text { ВВП по Российской Федерации (\%) }\end{array}$ & 1,07 & 1,10 & 1,10 & 1,11 & 1,0 \\
\hline $\begin{array}{l}\text { Удельный вес внутренних затрат на исследования и раз- } \\
\text { работки по приоритетным направлениям развития науки, } \\
\text { технологий и техники, в общем объеме внутренних затрат } \\
\text { на исследования и разработки по РФ (\%) }\end{array}$ & 67,9 & 68,6 & 71,0 & 70,5 & 69,8 \\
\hline Высокотехнологичные виды экономической деятельности & 60,6 & 76,7 & 76,4 & 72,4 & 56,8 \\
\hline Среднетехнологичные виды экономической деятельности & 65,2 & 46,3 & 65,1 & 49,9 & 79,6 \\
\hline Наукоемкие виды экономической деятельности & 68,2 & 69,0 & 71,5 & 71,4 & 70,4 \\
\hline
\end{tabular}

доля лиц с высоким уровнем профессионального образования в численности сотрудников, а критерием высокотехнологичной отрасли - показатель интенсивности НИОКР, то в случае соответствия обоим, предприятие одновременно может быть обозначено как наукоёмкое и высокотехнологичное.

Продуктовый подход рассматривает данные по конечной продукции и её наукоемкости; подход позволяет более точно оценить технологический уровень и классифицировать продукцию. являясь более детальным, дополняющим отраслевой. Если высокотехнологичность отрасли может различаться в зависимости от страны, то продукт не может находиться в разных странах в различных категориях. Также существуют продукты, изготавливаемые среднетехнологичными секторами, но входящие в перечень высокотехнологичных, что позволяет определить соотношение высоких технологий в отрасли, учитывая критерий продуктового подхода - исключение невысокотехнологичных продуктов, даже если они относятся к высокотехнологичной отрасли. На основе анализа соотношения величины расходов на НИОКР и выпуска товаров в 6 странах - США, Японии, Германии, Италии, Швеции, Нидерландах, была разработана классификация высокотехнологичной продукции. Актуальным является пересмотренный вариант четвертой редакции Стандартной международной торговой классификации (Standard International Trade Classification, SITC).

Патентный подход рассматривает высокотехнологичные патенты на основе Международной патентной классификации, хотя наличие патента на технологию не подтверждает внедрение технологии на рынке.

В работе А.В.Мисюры, представленные подходы обозначаются как нормативные, что предполагает определение оптимальных обобщен- ных критериев, показателей для классификации предприятий [15]. Выделены два подхода к определению высокотехнологичного промышленного предприятия: нормативный и позитивный, подразумевая под нормативным «что должно быть», под позитивным - «что есть». Позитивный направлен на установление причинноследственных связей, оказывающих влияние на результат деятельности предприятия. Основными критериями оценки при таком подходе являются: доля выручки от новых видов продукции и технологий, рост производительности труда, оценка совокупности факторов, соотношение технологического уровня предприятия и технологического уклада.

K основным признакам, определяющим предприятие как высокотехнологичное, относят также: применение передовых научных достижений, технические инновации, высокая квалификация сотрудников, небольшой жизненный цикл продукта, высокий темп изменений [6]. Отметим, что не только производство высокотехнологичных продуктов является определяющим фактором высокотехнологичного предприятия, но и управление производством, выработка соответствующих стратегий.

Параметрический подход направлен на рассмотрение критериев определения высокотехнологичного предприятия и осуществление параметрических расчётов [11]. Автором исследования рассмотрены следующие параметры: абсолютное значение факторной производительности, количество фирм на рынке, доля нематериальных активов в активах компании. Одним из итогов эмпирического исследования стал вывод, что изучение технологичности видов деятельности по показателям совокупной факторной производительности не определяет уровень технологичности. Потенциал технологического роста целесообразно отнести к кри- 
терию высокотехнологичного предприятия. В настоящее время высокая скорость изменений, обновления является одним из факторов, влияющих на конкурентоспособность компаний.

Подход на основе рейтинга является одним из способов выявления высокотехнологичных предприятий. Например, с 2012 года рейтинг «ТехУспех» при поддержке $\mathrm{AO}$ «РВК» формирует рейтинг быстроразвивающихся компаний в сфере высоких технологий. Основные показатели: темп роста выручки предприятий, уровень инновационности и экспортный потенциал [23].

На базе итогового показателя рейтинговой оценки проводится сравнительный анализ предприятий по каждому показателю, и в качестве исходного критерия выбрано условно эталонное предприятие с наилучшими результатами сравниваемых показателей. Данный подход является наиболее приемлемым при поиске инвесторов для определенных предприятий отрасли. Выделяются следующие группы показателей:

- оценки прибыльности хозяйственной деятельности;

- оценки эффективности управления;

- оценки деловой активности;

• оценки ликвидности и рыночной устойчивости.

По мнению В.Д. Марковой, С.А. Кузнецовой, к высокотехнологичным относятся компании, у которых интеллектуальная собственность и высококвалифицированный персонал являются главным активом. Также приводится уточнение, что высокотехнологичные компании в большинстве определяются ноу-хау и знаниями, и в меньшей степени материальными ресурсами и доступностью сырья. Среди особенностей отмечены высокие риски, сравнительно высокая доходность высокотехнологичного бизнеса и «привязка» потребителей, открытые инновации, ориентация на глобальный рынок и платформенные технологии [14].

Marco R.Di Tomasso и Stuart O.Schweitzer в исследовании о политике здравоохранения и развитии высокотехнологичного производства отмечена связь высокого уровня сотрудничества высокотехнологичной промышленности и университета, совместно реализующих деятельность через исследовательские альянсы, высокотехнологичные кластеры [29].

В Положении Республики Беларусь высокотехнологичная организация - «это организация, не менее половины продукции которой производится с использованием высоких технологий». Высокая технология определена как «технология, обладающая наивысшими качественными по сравнению с лучшими мировыми аналогами, пользующаяся спросом на рынке и удовлетворяющая формирующимся или будущим потребностям человека и общества». Таким образом, высокотехнологичные предприятия Республики Беларусь представлены как связующее звено между наукой и производством [17]

Исследование существующих подходов к определению статуса предприятия, как высокотехнологичного позволило систематизировать индикаторы высокотехнологичного предприятия. Существование высоких технологий обуславливает наличие обязательных требований к составу, качеству и способам использования ресурсных компонентов, соблюдение которых выделяет высокотехнологичные производства среди остальных.

Эффективная реализация бизнес-процессов высокотехнологичными предприятиями имеет свои особенности ввиду достаточно большого числа подсистем, интеграции науки и производства, высоких рисков, соответственно данный блок требует особого внимания при реализации деятельности высокотехнологичными предприятиями. В свою очередь, активизация технологически сложных процессов на предприятии предопределяет необходимость системного управления развитием предприятия и смежных по отношению к ним производств.

Таким образом, высокотехнологичное предприятие включает в себя высокий уровень функционирования основных блоков, к которым относятся: ресурсы, бизнес-процессы, управление, стратегически значимые результаты.

Высокотехнологичное предприятие, осуществляющее экономическую деятельность, на базе ресурсов (технологического ядра), обеспечивающих производственный, научно-исследовательский, кадровый, финансовый потенциал в совокупности, достигает эффективности функционирования и сохранения стабильного конкурентного преимущества в условиях изменений и Индустрии 4.0.

\section{Благодарности}

Исследование выполнено при финансовой поддержке РФФИ и БРФФИ в рамках научного проекта № 20-510-00002. 


\section{Библиографический список}

1. Постановление Правительства РФ от 05.08.2005 № 2473-П7 «Основные направления политики Российской Федерации в области развития инновационной системы на период до 2010 года»

2. Приказ Росстата от 15.12.2017 № 832 (ред. от 17.01.2019) «Об утверждении Методики расчета показателей «Доля продукции высокотехнологичных и наукоёмких отраслей в валовом внутреннем продукте» и «Доля продукции высокотехнологичных и наукоёмких отраслей в валовом региональном продукте субъекта Российской Федерации» (Приложение 1)

3. Указ Президента РФ от 9 мая 2017 г. № 203 “О Стратегии развития информационного общества в Российской Федерации на 2017-2030 годы”

4. Богданова М.Ф. Методы оценки результативности системы стратегического управления высокотехнологичным предприятия // автореф. дисс. на соиск. уч.ст.к.э.н. 2010

5. аврилова С.В. Концептуальные основы определения высокотехнологичного сектора экономики и функционирования высокотехнологичных компаний // Статистика и экономика. 2014 (№ 2). - с. 53-57

6. Гарина Е.П., Шиилевская Е.В., Андряшина Н.С. Изучение подходов к определению высокотехнологичного продукта в производстве // Вестник Мининского университета.- 2016 (№ 1)

7. Глушак Н.В. К вопросу о выделении высокотехнологичных отраслей и комплексов // Креативная экономика.- 2017.- Том 11.- № 4.- С. 497-508

8. Гораева Е.Н., Иванникова Е. М. Современные вызовы высокотехнологичных предприятий // Науки и бизнес: пути развития. 2019 - № 10(100). - с. 157-160

9. Доклад о человеческом развитии в Российской Федерации за 2018 год / под ред. С. Н. Бобылева и Л. М.Григорьева.- М.: Аналитический центр при Правительстве Российской Федерации, 2018. 172 с.

10. Дик П., Дик Н. Культурология: учебное пособие для вузов / П. Ф.Дик, Н. Ф. Дик.- Ростов н/: Феникс, 2006.$384 \mathrm{c}$.

11. Евсеева М.В.Исследование особенностей роста высокотехнологичных компаний на основе параметрического подхода // Journal of New Economy. Т. 20, № 5. С. 108-124.

12. Кузьмова Ю.С. Совершенствование механизма государственного регулирования предпринимательства на рынке высоких технологий / диссертация ... кандидата экономических наук: 08.00.05 / Кузьмова Юлия Сергеевна.-Санкт-Петербург, 2009.-206 с.

13. Леонтьева В. Механизм наращивания стоимости высокотехнологичной компании за счет интеллектуальной собственности // Корпоративное управление. 2014. - № 5. - с. 56-58

14. Маркова В.Д., Кузнецова С.А. Особенности развития высокотехнологичного бизнеса // Экономика Профессия Бизнес. 2016. № Спецвыпуск 1

15. Мисюра А.В. Высокотехнологичное промышленное предприятие: нормативный и позитивный подходы к определению // Journal of New Economy.2019. Т. 20, № 4. С. 88-107.

16. Норкина E.В. Методическое обеспечение реализации стратегии развития высокотехнологичного предприятия / автореферат дис.... кандидата экономических наук: 08.00.05 / Ин-т экономики УрО РАН.- Екатеринбург, 2007.- 26 с.

17. Положение «О порядке организации и проведения государственной научно-технической экспертизы разрабатываемых, привлекаемых и используемых технологий по отнесению их к новым и высоким, производств и предприятий, основанных на этих технологиях, к высокотехнологичным». утверждено Министерством экономики Республики Беларусь, Государственным комитетом по науке и технологиям Республики Беларусь от 24 апреля 1997 г

18. Татаркин А.И. Новая индустриализация экономики России: потребность развития и/или вызовы времени // Экономическое возрождение России. 2015. № 2 (44).- с. 20-32 Электронный ресурс. - URL https://e-v-r. ru/wp-content/uploads/2015/07/2015-2-44.pdf).

19. Сайт ООН.- Электронный ресурс. - URL https://www.un.org/ru/development/surveys/technology.shtml (дата обращения: 08.10.2020)

20. Федеральная служба государственной статистики.- Электронный ресурс - URL https://www.gks.ru/ folder/11186?print=1 (дата обращения: 08.09.2020)

21. Евростат - Электронный ресурс. - URL https://ec.europa.eu/eurostat/cache/metadata/en/htec_esms.htm (дата обращения: 08.10.2020)

22. Проблемы регулирования и правоприменительной практики, сдерживающие развитие высокотехнологиичных компаний в Российской Федерации.- Электронный ресурс. - URL http://doklad.ombudsmanbiz. ru/2020/6.pdf (дата обращения: 08.09.2020) 
23. Рейтинг «ТехУспех».- Электронный ресурс.- URL http://ratingtechup.ru/rate/2019/ (дата обращения: 08.09.2020)

24. Участники - компании проекта Минэкономразвития России «Поддержка частных высокотехнологических компаний-лидеров».- Электронный ресурс.- URL http://national-champions.ru/project/participants/ (дата обращения: 08.09.2020)

25. Технет. - Электронный ресурс. - URL https://nti2035.ru/markets/technet (дата обращения: 07.06.2020)

26. Kokoreva M., Stepanova A., Povkh K. Coukd high-tech companies learn from others while choosing capital structure // Электронный ресурс.- URL https:/www.hse.ru/data/2018/06/07/1149793461/62FE2017.pdf (дата обращения: 07.06.2020)

27. Revision of the high-technology sector and product classification/ Электронный ресурс.- URL https://www. cepal.org/sites/default/files/events/files/septima-reunion-gtci-revision-high-technology-sector-productclassification-thomas-hatzichronoglou.pdf (дата обращения: 08.09.2020)

28. Zakrzewska-Bielawska, Agnieszka. High Technology Company - Concept, Nature, Characteristics// Recent Advances in Management, Marketing, Finances. - 2010/01/01

29. Marco R.Di Tomasso, Stuart O. Schweitzer Health Policy and High-Tech Industrial Development // Learning from Innovation in the Health Industry. 